\title{
Perceptions and preferences of medical students regarding teaching methods in a Medical College, Mangalore India
}

\author{
Papanna KM1, *Kulkarni $V^{1}$, Tanvi D², Lakshmi V², Kriti L², B Unnikrishnan1, Akash S², Tejesh S², Sumit
} Kumar $\mathrm{S}^{2}$

1. Department of Community Medicine, Kasturba Medical College, Manipal University, Mangalore- 575001, India

2. Student, Kasturba Medical College, Manipal University, Mangalore- 575001, India

\begin{abstract}
Introduction: In the complex setting of a medical school it becomes essential to utilize an approach to teaching and learning that is best suited to the needs of the students. In developing countries like India, where there is an exponential increase of institutions catering to medical students, it becomes a challenge to teach to large number of students per class. Hence, research is needed to identify the needs of students in relation to their day to day learning activities.

Objectives: To understand the preferences and perception of medical students about the current methods of teaching, aids used for teaching and also identify barriers in learning as perceived by the students.

Method: A Cross-sectional study was carried out at Kasturba Medical College, Mangalore during May 2012. Study participants included $2^{\text {nd }}$ and $3^{\text {td }}$ year medical students. A semi-structured questionnaire was used to collect the information in relation to preferences and perceptions regarding teaching methods utilized for theory and clinical teaching. SPSS version 11.5 was used for analysis of data. The association between variables of interest was tested using Chi-square test.

Results: A total of 286 students ( $56.6 \%$ females and $43.4 \%$ males) participated with a dropout rate of $10.6 \%$. The study revealed that $71.3 \%$ of the students had an attendance above $75 \%$. The most preferred teaching method was Problem Based Learning (PBL) (71.4\%) as students felt that it enhanced lateral thinking while Didactic Lectures was the least preferred (32.8\%). The most preferred modality of teaching aid was found to be Black board preferred by $46.9 \%$ students. In learning rare signs and cases, students preferred video lectures (41\%) and mannequins $(75.9 \%)$ in learning clinical skills. The main barrier in theory learning identified was inappropriate teaching methods (15\%) and being new to clinical posting (38.5\%) in case of learning clinical skills.

Conclusion: The findings of the study suggest that a combination of traditional methods with other methods such as PBL, video lectures and mannequins could be an effective way of teaching theory and clinical skills.
\end{abstract}

Keywords: Perceptions and preferences, teaching methods, medical students, India

African Health Sciences 2013; 13(3): 808 - 813 http://dx.doi.org/10.4314/ahs.v13i3.41

\section{Introduction}

Learning is an active process in which the student and teacher have to work mutually to make the knowledge-sharing process enjoyable and easier for comprehension. For effective learning teaching should facilitate development of analytical approaches to a

*Correspondence author:
Vaman Kulkarni MD
Assistant Professor
Department of Community Medicine
Kasturba Medical College (Affiliated to Manipal
University)
Mangalore-575001
India
E-mail: drvaman_83@hotmail.com

problem and to address areas which pose difficulties for students. Thus, it becomes essential to utilize an approach to teaching and learning that is best suited to the needs of the students ${ }^{1}$.

In India medical colleges and universities are experiencing a significant growth in student enrollment. There are 229 recognized medical colleges in India, with an approximate number of 33,528 medical students graduating annually ${ }^{2}$. As a result, the medical educators face the challenge of teaching larger classes while maintaining and improving the quality of medical education ${ }^{3}$. Currently, didactic lectures are the method of choice to get across a large amount of theoretical information to a large group of learners at one time.

African Health Sciences Vol 13 Issue 3 September 2013 
Hence, most of the students see knowledge as something to be transmitted by the teacher to them. Teaching in most Asian countries is dominated by teacher-centered classrooms ${ }^{4}$. Concepts such as flexibility in learning, problem solving, critical thinking and independent learning are least recognized ${ }^{5}$.

There seems lack of consensus as to the best teaching and learning methods for medical students ${ }^{6}$. The emerging trend all over the world is to have a problem-based, integrated student-centered medical curriculum, demanding active participation from the students and facilitating self-directed learning. It is well known that no system could be fool proof in its application; it must be modified and applied to suit the needs of students in a particular infrastructure ${ }^{7}$. The objectives of this study was to understand the preferences and perception of medical students about the current methods of teaching, aids used for teaching and also identify barriers in learning as perceived by the students.

\section{Methods}

A Cross-sectional study was carried out at Kasturba Medical College, Mangalore. The study included second and third year medical students and was conducted during the month of May 2012. Kasturba Medical College is one of the affiliated colleges under the Manipal University, India, which along with Indian students caters to students of many foreign nations. The Kasturba Medical College has got class strength of 250 medical students enrolled every academic year. Considering the preference for lectures as an effective method of teaching at $40 \%$, an absolute precision of $15 \%$, and confidence interval of $95 \%$ the sample size of 267 was calculated. The final sample of 320 was obtained assuming a non-response rate of $20 \%$.

Students were selected by convenient sampling. A pre-tested, semi-structured questionnaire was administered to the students after obtaining written informed consents from them. The questionnaire included two parts, part 1-To assess preferences of the students related various teaching methods and teaching aids followed by part 2-To assess Perceptions regarding teaching methods utilized for theory and clinical teaching. The preference of teaching methods were rated using 5 point Likert scale $(1=$ strongly preferred, $2=$ preferred $3=$ neutral, $4=$ not preferred, $5=$ strongly not preferred).

The collected data was entered in Microsoft Excel and was analyzed using SPSS version 11.5. The data is expressed in as proportions and represented in the form of charts and tables. Median values at $50^{\text {th }}$ percentile were used to assess the preferences. The association between variables of interest was tested using Chi-square test.

Institutional Ethics Committee (IEC) clearance was obtained from IEC of Kasturba Medical College, Mangalore.

\section{Results}

A total 286 medical students participated in the study with a dropout rate of $10.6 \%$. Second year students constituted $166(58 \%)$ and $120(42 \%)$ were of third year. The female $162(56.6 \%)$ representation was higher in the study compared to males 124(43.4\%). Most of the students $(71.3 \%)$ had attended $>75 \%$ of the theory classes during the academic year.

\section{Preferences for Theory teaching methods}

Table 1 shows 204 (71.4\%) students rated problem based learning (PBL) as the most preferred method of theory teaching, followed by Socratic lectures (56\%), Jigsaw method (43.4\%) and didactic lectures $(32.8 \%)$ as the least preferred. Didactic lectures were preferred by least number of students as they felt they were monotonous \& boring $67(23.4 \%)$ and lacked student-teacher interactions 34 (11.9\%). Whereas, jigsaw method was not preferred as students felt self-learning was better $40(14 \%)$ and only some students could benefit by this method 34 $(11.9 \%)$.

Table 1: Preferences for theory teaching methods students $(n=286)$

\begin{tabular}{|c|c|c|}
\hline Teaching Methods & $\begin{array}{l}\text { Median }\left(50^{\text {th }}\right. \\
\text { Percentile)* }\end{array}$ & $\begin{array}{ll}\text { Preferred } & n(\%)\end{array}$ \\
\hline $\begin{array}{l}\text { Problem Based Learning } \\
\text { (PBL) }\end{array}$ & 2 & $204(71.4)$ \\
\hline Socratic Lectures & 2 & $160(56)$ \\
\hline Jigsaw Method & 3 & $124(43.4)$ \\
\hline Didactic Lectures & 4 & $59(32.8)$ \\
\hline
\end{tabular}

$*(1=$ strongly preferred, $2=$ preferred $3=$ neutral, $4=$ not preferred, $5=$ strongly not preferred $)$ 
From table 2 we could notice that $41.2 \%$ of students felt that PBL enhance lateral thinking and $40.2 \%$ felt that it helps in better clinical correlation. Socratic lectures were perceived to give students a chance to broaden their thinking $41.2 \%$ and freedom to voice/ opinion according to $29 \%$ of students. Didactic lectures were perceived to make learning easier by $43.7 \%$ of students whereas, jigsaw method was considered to give better understanding of the subject $25.2 \%$ and an opportunity for active learning $21.7 \%$.

Black board $(51.4 \%)$ was the most preferred teaching aid followed by Power point presentation (PPT) (40.9\%). Students felt that chalk and talk help them in understanding the subject better $(19.2 \%)$, could make teaching more interactive $(5 \%)$ and helps in holding their attention during teaching sessions $(3.5 \%)$.
Perceptions of clinical teaching methods

Majority of the students (81.5\%) rated bed side teaching as the most preferred method to learn clinical skills followed by mannequins $(75.9 \%)$, video lecturers $(67.9 \%)$ and the least preferred was role play $(36.1 \%)$ as shown in table 3 .

From table 4 students felt that bed side teaching was the best method to develop clinical skills $(52 \%)$ and communication skills $(49.6 \%)$. The use of mannequins according to the student could help them in practicing skills $(57.7 \%)$ and gain more practical experience $(32 \%)$. Whereas, video lectures could be used to demonstrate rare cases/signs (41\%) and also could be used when the patients are not available $(36.4 \%)$.

Table 2: Perception of students regarding theory teaching methods $(\mathrm{n}=286)$

\begin{tabular}{lll}
\hline Teaching methods & Perception & $\mathbf{n}(\mathbf{\%})$ \\
\hline Problem Based & Enhancement of lateral thinking & $118(41.2)$ \\
Learning(PBL) & Better clinical correlation & $115(40.2)$ \\
& Better student interactions & $49(17.1)$ \\
& Better student teacher interaction & $41(14.3)$ \\
Socratic lectures & Broadens thinking & $118(41.2)$ \\
& Freedom to voice /opinion & $83(29)$ \\
& Better student-teacher interaction & $72(25.2)$ \\
& Positive competitive spirit & $34(11.9)$ \\
Jigsaw method & Better understanding of the subject & $72(25.2)$ \\
& Opportunity for active learning & $62(21.7)$ \\
& Effective utilization of time & $44(15.4)$ \\
& Proper time utilization & $21(7.3)$ \\
Didactic lectures & Informative & $47(16.4)$ \\
& Indulge in other activities & $24(8.4)$ \\
& Proper time utilization & $21(7.3)$ \\
\hline
\end{tabular}

Table 3: Preferences for clinical teaching methods among the students $(n=286)$

\begin{tabular}{lll}
\hline Teaching Methods & $\begin{array}{l}\text { Median }^{\left(5_{0} \mathbf{t}^{\text {th }}\right.} \\
\text { Percentile) }^{*}\end{array}$ & Preferred n (\%) \\
\hline Bed-Side Clinics & 2 & $233(81.5)$ \\
Mannequins & 2 & $217(75.9)$ \\
Video Lectures & 2 & $194(67.9)$ \\
Role-play & 3 & $103(36.1)$ \\
\hline
\end{tabular}

$*(1=$ strongly preferred, $2=$ preferred $3=$ neutral, $4=$ not preferred, $5=$ strongly not preferred $)$ 
Table 4: Perceptions regarding clinical teaching methods among students $(n=286)$

\begin{tabular}{lll}
\hline $\begin{array}{l}\text { Teaching } \\
\text { methods }\end{array}$ & Perception & n (\%) \\
\hline Bed-Side teaching & Development of clinical skills & $149(52)$ \\
& Developing communication skills & $142(49.6)$ \\
& Learning bedside procedures & $85(29.7)$ \\
& Theory could be correlated better & $76(26.6)$ \\
Mannequins & Help in practicing skills & $165(57.7)$ \\
& Helps to gain more practical experience & $93(32.5)$ \\
& Increase the confidence & $78(27.3)$ \\
Video lectures & Demonstration of rare signs and cases & $117(41)$ \\
& Useful when patients not available & $104(36.4)$ \\
& Engages students' interest & $84(29.4)$ \\
& Identical experience for all & $65(22.7)$ \\
\hline
\end{tabular}

Table 5: Gender and preference of teaching methods

\begin{tabular}{llll}
\hline Teaching method & $\begin{array}{l}\text { Male(n=124) } \\
\mathbf{n ( \% )}\end{array}$ & $\begin{array}{l}\text { Female (n=162) } \\
\mathbf{n}(\mathbf{\%})\end{array}$ & p-value \\
\hline PBL & $76(61.3)$ & $128(79)$ & $0.004^{*}$ \\
Socratic Lectures & 63(50.8) & $98(60.5)$ & $<0.001^{*}$ \\
Jigsaw & $45(36.3)$ & $79(48.8)$ & 0.08 \\
Didactic Lectures & $31(25)$ & $28(17)$ & 0.20 \\
Bed-Side Teaching & $93(75 \%)$ & $142(87.7)$ & $0.01^{*}$ \\
Mannequins & $86(69.4)$ & $132(81.5)$ & $0.03^{*}$ \\
Video Lectures & $76(61.3)$ & $118(72.8)$ & $0.001^{*}$ \\
Role Play & $44(35)$ & $59(36)$ & $0.003^{*}$ \\
\hline
\end{tabular}

Pearson's Chi-square $X^{2 *}(\mathrm{p}$-value $<0.05)$

Gender and preference of teaching methods

Table 5 shows an overall difference in preference for teaching methods between boys and girls. The preference for PBL(79\%), Socratic lectures( 60.5\%), bedside clinics (87\%), mannequins (81.5), video lectures $(72 \%)$ and Role play $(36 \%)$ as teaching methods was higher among the girls when compared to preference for $\operatorname{PBL}(61.3 \%)$,Socratic lectures (50.8\%), bedside clinics(75\%), mannequins $(69.4 \%)$, video lectures (61.3) and Role play (35\%) among boys. The difference in preferences for the above teaching among genders was also statistically significant ( $\mathrm{p}$-value $<0.05)$.

\section{Barriers in learning as identified by students}

The students felt long monotonous lectures with inappropriate teaching methods (15\%) and large class room size with excessive disturbance $(10.8 \%)$ as the main barriers in learning theory sessions. Whereas, being new to clinical postings (38.5\%) and lack of space $(35 \%)$ were identified as barriers in learning clinical skills.

\section{Discussion}

The study identified some of the areas of current teaching which could be improvised for effective teaching. Our study had a slightly higher representation of females $(56.6 \%)$ as compared to males which was similar to the study conducted by AdibHajbaghery M.et al with $52.5 \%$ and in another study conducted by Carpenter JM et al female representation was $82 \%{ }^{3,5}$. The reason for this difference in our study was because the proportion of female students gaining admission at our institution is higher when compared to males.

Our study also found that an overwhelming majority of the students preferred problem based learning would reinforce the students' interest as they felt that it enhanced their lateral thinking, gives a better correlation between theory and clinical postings and also improved student interactions among each other as well as the teacher.

Students in our study preferred Socratic lectures as they felt it could improve students' thinking, gives them the freedom to voice their opinion, a 
better platform for student-teacher interaction and a positive competitive spirit. A study conducted by Jason M.C in South Carolina also showed that Socratic lectures was considered as the most valuable method and the students stated that it forces them to be alert, allows them to contribute and ask questions and also not as boring as lectures ${ }^{3}$. In another study conducted by Adib-Hajbaghery M.et al, it was noted that Socratic lectures facilitated active participation promotes learning ${ }^{5}$. Hence, Socratic lectures could be considered as an effective alternative to the conventional Didactic lectures.

It was surprising to find that black board was the most preferred teaching aid followed by PPT in our study, these findings were different from the findings of the study conducted by Lalit Mohan et al which found that both the methods were almost equally preferred thought mix of aids were the most preferred $^{8}$.Whereas, the Pakistan study conducted by Atif Mahmood found that PPT was the most preferred aid with white board being the least favorite? The preference for black board in our study could be because PPT have replaced the traditional chalk and talk method which needs in-depth understanding of the subject and confidence.

As expected majority of students preferred Bed Side teaching, for the reasons that it was the most efficient way for them to develop clinical and communication skills, learn bedside procedure and correlate better with the knowledge acquired during classrooms. They also voiced their preference for mannequins during clinics as it increases their confidence; helps gain more practical experience and practicing those skills. However, the cost, infrastructure required for their proper storage and maintenance, time and space required for teaching the skill to each student, individually could be some of the constrains for the institutes. The students also suggested video lectures as another method which could be included as part of teaching methods. A randomized control trial comparing live lecture and video podcast conducted in United kingdom by Schreiber EB et al showed that there was no significant difference on multiple choice questioning immediately after the session. Hence, the video lectures could provide the students with flexibility in learning as it provides a chance to review and repeat the sessions ${ }^{10}$.

Students identified inappropriate teaching methods $(15 \%)$ and large class room size with excessive disturbance $(10.8 \%)$ barriers in class room learning. Some reports have shown that students' inactivity in traditional teacher-centered classes would make them bored and exhausted that consequently would decrease their concentration and learning and finally would result in their absence from the classroom $^{11}$

A statically significant difference was found between the male and female students. The reasons for this could be identified by conducting a focused group discussion to gain a better understanding about the differences in preferences across the genders. Disinterest among the students to participate and subjective nature of some of the questions could be the limitations of our study.

\section{Conclusion}

The findings of the study suggest that a combination of traditional methods with other methods such as PBL, video lectures and mannequins could be an effective way of teaching theory and clinical skills. The authors would like make these recommendations which include the following. The classes could be made more interesting and interactive by giving Multiple Choice Questions related to the topic at the beginning or giving clinical scenarios. Teachers should be encouraged to use chalk and talk more frequently during teaching sessions. The teaching methods such as PBL, video lectures and Mannequins should be used in combination for effective teaching. Orientation classes to students fresh to clinics could help the students in understanding the bedside clinics better and the other barriers identified by the students needs to be addressed by the management.

\section{References}

1. Saville B, Zinn T, Neef N, Van Norman R, Ferreri S. A comparison of inter-teaching and lecture in the college classroom. Journal of Applied Behavior Analysis.2006; 39: 49-61.

2. Medical Council of India Annual Report 20092010. Available at URL: http://mciindia.org/ aboutmci/annualreports.aspx (Accessed on 30/ 04/2012)

3. Carpenter JM. Effective teaching methods for large classes. Journal of family and consumer sciences education 2006; 24 (2):13 -23.

4. Zhenhui R. Matching Teaching Styles with Learning Styles in East Asian Contexts. The Internet TESL Journal. 2001;7(7). http://iteslj.org/ Techniques/Zhenhui-TeachingStyles.html) (Accessed on 30/04/2012) 
5. Adib-Hajbaghery M, Aghajani M . Traditional Lectures, Socratic Method and Student Lectures: Which One do the Students Prefer? Webmed Central Medical Education. 2011; 2(3):

6. Veerapen K, McAleer S. Students' perception of the learning environment in a distributed medical programme.2010. Available at URL: http://med-ed-online.net/index.php/meo/ article/view/5168 (Accessed on 30/04/2012)

7. Johnston JM, Schooling CM, Leung GM. A randomized control trial of two educational modes for undergraduate evidence- based medicine learning in Asia. BMC Med Educ. 2009 Sep 29;9:63

8. Ghosh S. Combination of didactic lectures and case-oriented problem solving tutorials towards better learning: Perceptions of students from a conventional medical curriculum. Advances in physiology Edu.2007 Jun; 31:193-7

9. Mohan L, Ravi Shankar P, Kamath A, Manish MS, Eesha BR. Students' Attitudes Towards The Use Of Audio Visual Aids During Didactic Lectures In Pharmacology. Journal Of Clinical And Diagnostic Research.2010;4:3363-3368

10. Atif M,Famidha K,Mukarram A,Saima E,Kamran A,Masood AQ.Perception and
Preferences of undergraduate medical students regarding the use of contemporary teaching aids at Dow international medical college,Karachi. Journal of University of Health Sciences Karachi.2011;5(1):34-36

11. Schreiber EB, Fukuta J, Gordon F. Live lecture versus video podcast in undergraduate medical education: A randomised controlled trial. BMC Medical Education 2010;10:68

12. Fasihi Harandi T., Aziz Zadeh Forozi M., Mohammad Alizadeh S., Ghazanfari M Z. Effective factors on theoretical class attendance according to nursing and midwifery students point of view, Kerman, Razi School of Nursing and Midwifery. Strides in Development of Medical Education 2007; 4(2): 100-7. 